\title{
Chapter 4 \\ Science as a Commons: Improving the Governance of Knowledge Through Citizen Science
}

\author{
Maite Pelacho, Hannot Rodríguez, Fernando Broncano, Renata Kubus, \\ Francisco Sanz García, Beatriz Gavete, and Antonio Lafuente
}

\begin{abstract}
In recent decades, problems related to the accessibility and sustainability of science have increased, both in terms of the acquisition and dissemination of knowledge and its generation. Policymakers, academics, and, increasingly, citizens themselves have developed various approaches to this issue. Among them, citizen science is distinguished by making possible the generation of scientific knowledge by anyone with an interest in doing so. However, participation alone does not guarantee knowledge generation, which represents an epistemological challenge for citizen science. Simultaneously, economic and socio-institutional difficulties in science governance and maintenance have grown. To solve those problems, several market elements have been introduced, a solution rejected by those who consider science as a public good that states must guarantee. Alternatively, research and work on the commons are growing worldwide, the concept being extended from natural
\end{abstract}

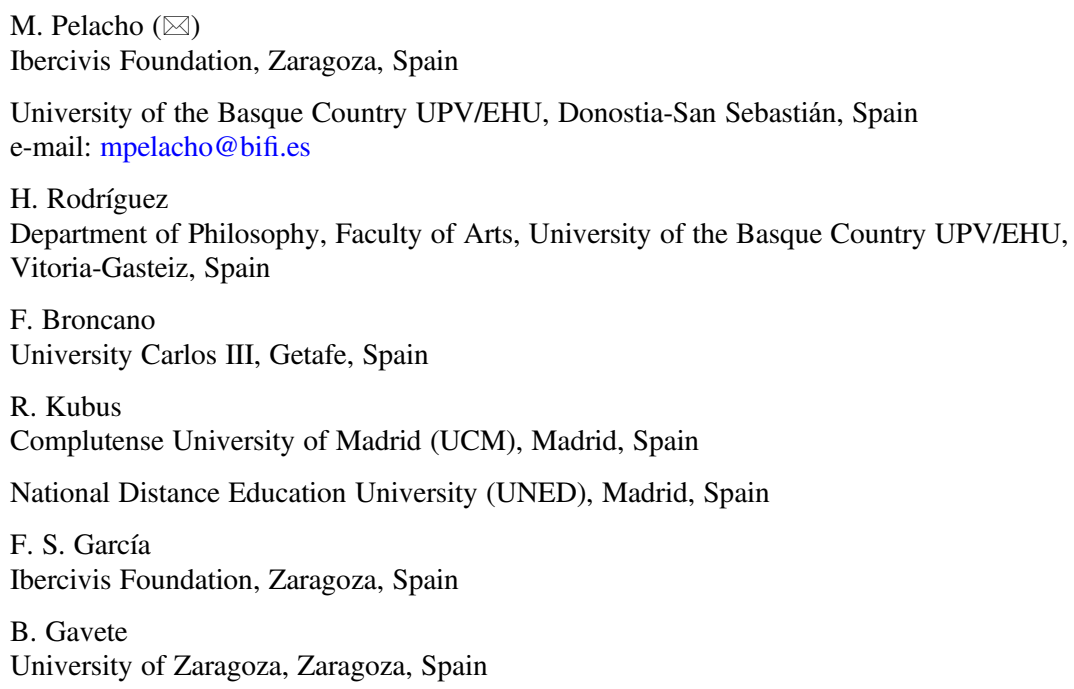


resources to knowledge resources. In this chapter, we propose science as a commons, underlining the essential role of citizen science. Difficulties also apply to citizen science itself, but the increasing development of a multitude of projects based on cooperation favours the conditions required for its sustainability and quality.

Our philosophical proposal is based on empirical knowledge about citizen science coupled with socio-economic concepts, according to a sociopolitical epistemology.

Keywords Science governance $\cdot$ Open science $\cdot$ Political epistemology $\cdot$ Social epistemology $\cdot$ Knowledge commons

\section{Introduction}

In recent decades, problems and questions related to the governance of science, particularly to its sustainability and accessibility, have multiplied not only with regard to the acquisition and dissemination of knowledge but also its generation and co-production.

We can consider the case of communities affected by environmental, health, and broader societal issues, whose interests are not prioritised by those in power. Let us also consider the appropriation, by certain industries, of the knowledge of traditional and local communities, in such a way that they are excluded from access to knowledge that they themselves have generated. Or the circumstance, also paradoxical, produced by the increase in the price of scientific journals to which universities and research centres have been subjected to in order to be able to access the knowledge that, once again, they themselves have generated. Another major area of tension related to the sustainability of science is how to address intellectual property management in a way that is compatible with the open science model. Dealing with growing data sets involves serious ethical and legal privacy issues. The funding of scientific institutions and research programmes is an issue of ongoing concern and debate that requires research.

Before continuing, it is necessary to clarify that talking about science and scientific knowledge requires at least three aspects: the generation of knowledge itself, the means for this generation, and the communication of results.

In recent decades, all the above-mentioned issues, along with many others, have been posed in relation to the evolution of legislation and technology, as well as the underlying culture. Other questions include what does excellent science mean; how should funding for science be managed; what kind of knowledge can be patented; and, what is meant by open science. These pragmatic questions are associated with ongoing philosophical research (e.g. epistemological and ethical) that explores the differences between various types of knowledge: how they are generated; how they are validated and by whom; who owns them; where, and how, is science undertaken and why.

Citizen science, as a cross-cutting and continuously evolving methodology, can offer compelling answers to these questions. The development of a multitude of collaborative projects, in different areas, scopes, subjects, etc., that favour the 
sustainability, accessibility, and quality of scientific knowledge, must be considered to achieve the optimal governance of science.

The aim of this chapter is to provide an answer to the question of how to achieve an improved governance of science through citizen science. We propose to understand and manage science as a commons. This proposal is based on analyses that overcome the public-private dichotomy, where the sole respective actors are the state and the market, to achieve an improved governance of science through citizen science.

The role of citizen science is crucial to this proposal, as it involves a research practice in which every citizen, entity, and community can find their place and share responsibility. Our philosophical proposal is based on our empirical knowledge of citizen science and on the growing studies, both theoretical and empirical, on the commons.

The term 'commons' refers to a form of community management of a shared resource. Good governance of the commons implies that the communities who share access and/or use of a resource manage their behaviour through a self-established set of rules (Ostrom 1990; Madison et al. 2019). The commons results from a collaborative, open, and experimental process that necessarily involves the community of practice. Each community not only produces the commons but is simultaneously produced in the common acting (Dardot and Laval 2019).

Justifying our thesis requires philosophical argument in different fields. We will start with a first approximation to the relationship between citizen science and the commons. The chapter continues with a philosophical consideration of the nature of science, underlining its social structure. Then, it addresses key features of the methodologies of citizen science. On this basis, we will develop our proposal, explaining the central commons and knowledge commons concepts, and conclude that citizen science should also be considered a commons. Finally, we summarise the main challenges in this field alongside recommendations for citizen science projects and for wider society.

\section{Citizen Science and the Commons: Old and Entangled Concepts}

Different conceptions of science and its environments have co-evolved alongside new forms of knowledge co-production (Jasanoff 2003). In this sense, various approaches have been proposed regarding science, in the more general context of co-production (Ostrom and Ostrom 1977) and the participatory turn (Jasanoff 2003). These approaches include, among others, the extended peer community (Funtowicz and Ravetz 1997), a new social contract between science and society (Gibbons 1999), public engagement with science (Leshner 2003), socially robust science (Nowotny et al. 2005), citizen science (Irwin 1995; Bonney 1996), wellordered science (Kitcher 2001), and, more recently, open science (e.g. Moedas 
2015). All these approaches share the underlying idea of giving voice to anyone concerned about scientific and technological issues that affect them (Fischer 2000).

Regarding citizen science, it should be noted that it does not only consist of such relevant issues as establishing a greater multidirectional dialogue between all parties involved; attending to citizens' demands for decision-making on scientifictechnological and risk issues, and providing complementary socio-ethical approaches to scientific-technological ones. These approaches are, indeed, necessary and lead to meaningful participation in the deliberation and influencing of political pathways (Fischer 2000). But, citizen science practices also represent a substantial step forward in the democratisation of science, by making possible generation of knowledge by supposedly non-expert agents in all stages of the scientific process. In doing so, diverse capacities to undertake science are recognised and built (Leach et al. 2005). In addition, citizen science is not a new practice; there exist impressive examples throughout history related to active citizen participation, not only in the environmental field but also in diverse areas such as meteorology, astronomy, and oceanographic science (see Sanz et al., Chap. 21, this volume).

Nevertheless, how to reconcile the contribution of a large number of non-professional agents in knowledge generation with the quality of this knowledge is a complex issue. Even so, there is a growing body of literature showing the relevance of citizen science for academic research.

Besides that, closely related to the already mentioned issues, society faces difficulties in the governance and maintenance of the scientific-technological system, with consequences that go beyond the purely economic. Thus, there is a complex intertwining between epistemic issues (which question the validity of knowledge) and sociopolitical issues (which question who can be considered legitimate and responsible agents of its production) (Broncano 2006). As a supposed solution to this tension, there has been an increase in the incorporation of market elements in science management (Radder 2010; Vermeir 2013), such as intellectual property rights and modes of patenting and licensing. At the same time, such commercialisation has been frequently objected to, highlighting the nature of science as a public good (Callon 1994; Nowotny et al. 2005; Mirowski 2018), with various arguments to prevent or stop its privatisation.

As an alternative solution to the conflicts - particularly in science -surrounding the public-private dichotomy, in the last decades, work and research on commons governance and collective action (Ostrom 1990) has developed in academia and in activism, law, and politics (see a complete set of references in Dardot and Laval 2019). In particular, Dardot and Laval, in their work Common (2019), explain the various meanings of the commons concept and its historical evolution.

Moreover, the commons concept has expanded from natural resources (fisheries, pastures, etc.) to the knowledge commons (Hess and Ostrom 2007) since the beginning of the twenty-first century, specifically, to scientific knowledge (Vermeir 2013; Irzik 2013). This includes collaborative methodologies, for example, data production in citizen science projects (Weber et al. 2019) and data analysis in online citizen science projects (Madison 2014). 


\section{Science and Knowledge: Networks of Cooperation}

In this section, we first carry out a brief analysis of the current systems of scientific knowledge dissemination, as well as its generation, from the viewpoints of social epistemology (Goldman 1999) and political epistemology (Broncano 2006). Next, we introduce the diverse methodologies in citizen science projects which contribute to improved development and governance both of physical resources and scientific systems.

\section{Citizen Science Highlighting the Social Structure of Science}

Willard V.O. Quine was one of the most influential twentieth-century philosophers of science, chiefly due to his image of science as a vast network of beliefs whose periphery connects with reality, while the interior is populated with theoretical hypotheses (Quine and Ullian 1970). From Quine's perspective, science is not fragmented into separate fields. Thus, an empirical result in a certain research field may influence a theoretical hypothesis in a different field.

The metaphor of the network does not only apply to the meaning of theoretical terms or to the relationship between theories and experiences but also to the construction of science as collective work. An enormous number of people obtain data, generate hypotheses, make calculations, teach other people, criticise current theories, explore ideas apparently distant from their specialty, join in discussions over coffee, and, in short, create social networks on which the network of beliefs that shapes our scientific knowledge is sustained.

Boutang (2011) proposes a metaphor to account for the way in which knowledge is produced as cognitive social work: pollination. In the case of the knowledge society, cognitive pollination refers to a vast network of interactions - educational, suggestive, imitative, and collaborative. Society reproduces itself through the flow of information, contributions, and small discoveries that generate the accumulation of knowledge. The globe becomes a vast campus of knowledge - where specialised professional research intersects with transdisciplinary spaces - that allows unlikely cognitive fertilisations. The image of pollination, therefore, suitably represents the situated and social nature of epistemic agency. Epistemic agency, or in other words, the ability to form true beliefs from intellectual capacities, is a faculty that has both a personal and an interdependent and collective dimension. Each researcher boosts knowledge, at least partially, by relying on epistemic resources shared with the rest of the scientific community and, beyond that, with the rest of society. Knowledge is always a situated and interdependent activity, both in the use of resources that have been donated by others and in the evaluation of the result of one's own work. This interdependence is not based on a hierarchical or pyramidal structure of authority but on a vast network of acts of sharing, criticising, legitimising, and changing epistemic resources. It is the network's shape that represents the image of pollination: 
knowledge is spread in sometimes improbable and unpredictable ways because it germinates in diverse and distant spheres. This image does not completely blur the distinction between experts and laypersons; on the contrary, what it produces is an extension of the distinction. We are all experts in some domain, in that we produce reliable beliefs, and at the same time we are all laypersons regarding our cognitive dependencies on other people's work.

Participation in science is grounded in both the nature of human knowledge and cognitive activity. The idea of a network of beliefs, supported by a social network that continuously pollinates and germinates creativity, can help us to think about citizen science in less hierarchical ways; as based on the social division of labour between expert scientists and lay persons. Science, technology, and society studies (STS), developed mainly since the 1980s, show many pollination phenomena, such as activism, that point to blind spots in science and identify new avenues of research (Hess 2007; Frickel et al. 2009). Whether this ideal is realised depends on multiple factors, including educational and institutional. Sometimes, institutional design -for example, structures in which not everyone has a voice - impedes cognitive cooperation through difficulties in accessing common epistemic resources. Practices can also lead to the exclusion of others due to competitive or epistemic arrogance. In a certain sense, the original view of science as part of the public sphere that gave rise to modern science in the Enlightenment and the nineteenth century has been lost (see David 2008).

The impulse to citizen science must be part of a change in perspective on the general redesign of all our institutions of production of science and technology. That change must be focused on stimulating cooperation. At the beginning of the nineteenth century, Humboldt introduced an educational reform based on the unity of the Wissenschaft (Hohendahl 2011), in contrast to the concept of science of the Enlightenment, which was much more oriented towards the separation of areas and objects. From Humboldt's reforms emerged science as we know it. Despite its shortcomings in what could still be seen as an elitist arena, the core meaning of those reforms was and is very relevant. Those proposals can be extended to the whole of education, uniting research and teaching at all levels, and to the broader epistemic life of our societies.

Incremental innovations in all fields, from scientific theory to diverse technologies, produced the paradox of a progressive and unstoppable conversion of knowledge into a form of capital. The shape of science has been drifting towards a metric system where indicators measure research impact and researchers orient their lives towards securing good indices rather than the unpredictable task of advancing knowledge. This reorientation appears to be driving a steady decline in the motivating factors and affective bonds that sustained the epistemic communities of the twentieth century, when in a few decades there were surprising scientific and technological revolutions in all fields.

Faced with this trend, the joint actions of production and dissemination of knowledge have been progressively recognised by initiatives that understand science as a commons. In the Humboldtian model, researchers and professors are joined together. In an increasingly complex society, collaboration in the production and 
reproduction of knowledge involves new actors and sectors, such as students in training, research managers, innovative companies, hospitals, and public services. The epistemic cooperation of all personnel is essential, and the flow of knowledge is fundamental to institutional functionality. Beyond that, we find a growing awareness that the networking that sustains science can substantially benefit from the contribution of informal networks of citizens who draw attention to abandoned or undone science (Hess 2007). Their traditional knowledge can provide new lines of research, and even amateur work can produce relevant contributions. The frontiers between science and the public are blurring, opening up new ways of extending knowledge networks to wider society. Thus, citizen science is presented as a paradigm of this new configuration of borders: nowadays, many research projects in diverse areas cannot be successful without citizen participation.

\section{The Core of Citizen Science Methodologies}

The methodologies currently used in citizen science are diverse and ever evolving. We are interested in projects that provide examples of good practice in the generation of scientific knowledge, not only because of their research results but also in terms of their accessibility and their sustainability.

We group some examples of activities (see Table 4.1), together with their methodologies, according to a simple classification to illustrate our ongoing thesis about understanding science as a commons. The first type includes practices related to environmental management and the preservation of natural resources; the second type refers to projects whose aim is to achieve better epistemic results in different areas of knowledge; finally, a third type includes those activities seeking to improve citizen science itself. Our intention is not to introduce a new typology of citizen science projects, among the many existing ones. Rather, we seek to clarify, starting with empirical observation, the ways citizen science can contribute to better scientific knowledge and sustainability of the scientific system.

In this small sample, we consider contrasting activities and methodologies. For example, in distributed computing projects participants contribute simply by donating computer processing time (e.g. Einstein@Home), whereas other projects require the participation of members of society as a whole: policymakers, academic scientists, industry and business representatives, and local communities (e.g. SnowChange). Other examples include projects funded by European funding programmes (e.g. EU-Citizen.Science) and independent projects that are sustained purely by participants' contributions (e.g. Biodiversidad Virtual). We have incorporated bottom-up (e.g. Biodiversidad Virtual) and top-down projects in the natural sciences (e.g. Galaxy Zoo) and the humanities (e.g. Old Weather). There are also online (e.g. Debian) and offline activities (e.g. ECSA conferences), as well as those that combine both methodologies (e.g. Model Forest).

Both objectives and methodologies have been intentionally shown here as separate in an analytical way, but usually they are intermingled in many projects. 
Table 4.1 Citizen science activities according to their main objective, including diverse methodologies

\begin{tabular}{l|l|l}
\hline Main objective & Methodologies & Good practices \\
\hline $\begin{array}{l}\text { Type 1 } \\
\text { Better management of } \\
\text { natural resources }\end{array}$ & $\begin{array}{l}\text { Contributing with pictures. Identifying and } \\
\text { cataloguing them } \\
\text { Community-based methodologies, which combine } \\
\text { academic science with local knowledge: contribut- } \\
\text { ing with data, stories, local culture, etc. } \\
\text { Promoting focus groups, interviews, co-created } \\
\text { actions and reports, as well as local, regional, } \\
\text { national, and international meetings }\end{array}$ & $\begin{array}{l}\text { Model Forests } \\
\text { GAP2 } \\
\text { SnowChange } \\
\text { SEO/BirdLife }\end{array}$ \\
\hline $\begin{array}{l}\text { Type 2 } \\
\text { Better research results }\end{array}$ & $\begin{array}{l}\text { Identifying and classifying systems (galaxies, } \\
\text { planets, cells, animals, and plants, etc.) on online } \\
\text { platforms } \\
\text { Transcribing handwriting texts or translating doc- } \\
\text { uments } \\
\text { Serious games } \\
\text { Distributed computing }\end{array}$ & $\begin{array}{l}\text { Galaxy Zoo } \\
\text { Old Weather } \\
\text { Einstein@ Home }\end{array}$ \\
\hline $\begin{array}{l}\text { Type 3 } \\
\text { Better management of } \\
\text { citizen science projects }\end{array}$ & $\begin{array}{l}\text { Constitution of associations, observatories of citi- } \\
\text { zen science, etc. } \\
\text { Collaborative networks for supporting other pro- } \\
\text { jects } \\
\text { Research and/or elaboration - ideally with citizen } \\
\text { participation - of guidelines on communication, } \\
\text { ethical issues, quality of data, dataset management, } \\
\text { among other issues }\end{array}$ & $\begin{array}{l}\text { ECSA confer- } \\
\text { ence } \\
\text { Debian } \\
\text { EU-Citizen. } \\
\text { Science }\end{array}$ \\
\end{tabular}

Activities whose main objective is the conservation of natural resources directly involve the generation of scientific knowledge: ecological and socioecological knowledge, as well as other types of knowledge (e.g. legal, economical, socioethical). The projects that address producing best practice guidelines and the associations that seek to support citizen science are largely initiated by participants and/or project managers. Many of them aim to improve environmental management, ethical aspects, and/or knowledge generation. To illustrate good practices, we have chosen both projects ongoing for many decades (e.g. SEO/BirdLife) and others limited in time and already completed (e.g. GAP2). Results co-created by the diverse involved communities include scientific publications and methodologies that can be used in their respective research areas and beyond. Some of these projects are explained in more detail in Table 4.2.

Although it would be convenient to speak of citizen sciences (Lafuente and Estalella 2015) to account for the many existing types, citizen science is frequently understood as a scientific methodology that encompasses diverse areas of knowledge. Two points are clear: first, citizen science consists essentially of undertaking research; and, second, it is carried out by citizens, that is, people who are usually not professional scientists, although in many cases they work together. We agree with Haklay (2015, p. 11) when he states, in view of the diverse practices and definitions of citizen science, that 'what is common to these definitions is the collaboration 
Table 4.2 Examples of citizen science projects constituting science as a commons

\begin{tabular}{|c|c|c|}
\hline Main objective & Project & Description \\
\hline $\begin{array}{l}\text { Type } 1 \\
\text { Better managing nat- } \\
\text { ural resources }\end{array}$ & $\begin{array}{l}\text { Model } \\
\text { Forests }\end{array}$ & $\begin{array}{l}\text { The Model Forest approach was first developed by the Gov- } \\
\text { ernment of Canada in the early 1990s. It was in response to a } \\
\text { period of intense conflict in the forest sector when forest } \\
\text { workers, governments, environmentalists, indigenous peo- } \\
\text { ples, and communities were in conflict over forest resources } \\
\text { and how to manage them sustainably. } \\
\text { A Model Forest promotes partnerships in a forum where a } \\
\text { range of values and interests can be represented and partners } \\
\text { with a common goal of sustainable development can share } \\
\text { new ideas. Each forest is intended to be a dynamic 'model' } \\
\text { from which others can learn and advance their sustainability } \\
\text { goals; finding common solutions to issues such as biodiver- } \\
\text { sity protection, conservation, and economic stability. } \\
\text { (Source: International Model Forest Network n.d.) }\end{array}$ \\
\hline $\begin{array}{l}\text { Type } 2 \\
\text { Better research } \\
\text { results }\end{array}$ & $\begin{array}{l}\text { Galaxy } \\
\text { Zoo }\end{array}$ & $\begin{array}{l}\text { Galaxy Zoo was founded in } 2007 \text { by astronomers at the } \\
\text { University of Oxford to enlist volunteers to assist with data } \\
\text { classification to better understand the evolution of galaxies. } \\
\text { Based on the number of participants (hundreds of thousands), } \\
\text { the amount of data processed, the speed and accuracy in } \\
\text { completing the project, and the number of research papers } \\
\text { produced, it has been a success. Madison (2014) explains that } \\
\text { the key reason for its effectiveness as a commons is due to its } \\
\text { social organisation. Its 'big community' was guided by a } \\
\text { vision of a specific organisational solution to a specific } \\
\text { research problem, initiated and governed by professional } \\
\text { astronomers in close collaboration with volunteers. }\end{array}$ \\
\hline $\begin{array}{l}\text { Type } 3 \\
\text { Better managing citi- } \\
\text { zen science } \\
\text { projects }\end{array}$ & Debian & $\begin{array}{l}\text { The Debian Project is an association of developers and users } \\
\text { whose common goal is to create a free operating system } \\
\text { called Debian. About a thousand developers around the world } \\
\text { volunteer to help create Debian. The project started in 1993, } \\
\text { seeking to be collaboratively and carefully created, } \\
\text { maintained, and supported. It began as a small, tightly knit } \\
\text { group of free software hackers, and gradually grew into the } \\
\text { large, well-organised community that continues to operate } \\
\text { today. At Debian, people spend their free time writing soft- } \\
\text { ware, packaging it, and then donating it; their motivations } \\
\text { include: to help others, to learn more about computers, to } \\
\text { avoid the inflated price of software, in return for the excellent } \\
\text { software they receive from others, or simply for fun. In } \\
\text { academic institutions and in citizen science projects many } \\
\text { people create free software to facilitate their research results } \\
\text { being used more widely. (Source: Debian n.d.) }\end{array}$ \\
\hline
\end{tabular}

beyond institutional boundaries, the activities that are part of the scientific process, and the cooperation between members of the public and professional scientists'. In this sense, Haklay et al. (Chap. 2, this volume) understand as restrictive certain conceptualisations of citizen science that confine it within the established research system. 
We understand that cooperation - key for the constitution of a commons - is at the core of the diverse practices of citizen science. In the previous section, we considered the structures that make this cooperation possible, delving into the nature of science shaped as an open network. Further on, it will be necessary to deepen the meanings, possibilities, and implications of cooperation, particularly in science. But, before that, we need to address the proposal of knowledge as a commons.

\section{Knowledge as a Commons for Better Governance of (Citizen) Science}

At this point, we will deal with the notion of openness and its close relationship with citizen science. The issue of openness in science will lead us to deepen the approach of the commons. In this analysis, we will argue our proposal to consider science and citizen science itself - as one of the knowledge commons. Throughout this section, we present examples of citizen science projects to illustrate our proposal.

\section{Commons: Beyond Public Goods}

In the section on networks of cooperation, we considered the expansion of the knowledge network system underlying the growing phenomenon of citizen science. That expansion leads to an increase both in the number of agents and in the flows of production and dissemination of knowledge. In this context, openness - as opposed to enclosure or exclusion - is key if we want knowledge to be as accessible, disseminated, and co-generated as possible. It could then be inferred - as has been widely assumed by Western culture, particularly in the second half of the twentieth century - that knowledge is a public good like the light of a coastal lighthouse or a road network. A public good is a resource open to use by all, including those who may not contribute to its existence or maintenance. Furthermore, a public good is managed by state institutions.

The mainstream view of social dilemmas (e.g. tragedy of the commons, the prisoner's dilemma, etc.) and the possibilities of collective action takes for granted the selfish and opportunistic behaviour of individuals, which leads to the deterioration or loss of shared goods through over-exploitation. This justifies the intervention of external agents to ensure the maintenance of open, shared resources. This perspective proposes a scheme of governance with only two institutional forms, the state and the market, to address collective problems.

According to the mainstream view in economics, resources are classified into two types with respect to their intrinsic properties. On the one hand, there are private goods. These are excludable and rivalrous. On the other hand, there are public goods. These are non-excludable and non-rivalrous. However, a decade later this 
classification was shown to be insufficient, since it does not account for the case of club goods. These can be used to understand the basic properties of goods, namely, excludability and rivalry (also known as subtractability). Consider the example of the theatre. You can access the play only if you pay for the ticket. The play is an excludable good, because not everyone can access it. Nevertheless, the fact that other people enjoy the play at the same time does not diminish your enjoyment. The play is a non-subtractable good, because the fact that others use it does not prevent you from using it too.

However, in the 1970s, Ostrom and her team proposed an alternative thesis, based on their wide empirical studies. They introduced the concept of the common goods, simply known as the commons. These are excludable resources, as public goods, but subtractable, as private goods. Pastures and forests are examples of common goods. They are excludable because in principle everyone can access them. Nevertheless, they are also subtractable to use. The grass or the wood consumed by one user cannot be consumed by another user. In addition, the introduction of the commons led to a reconceptualisation of excludability and subtractability as gradual properties. Some goods are more or less excludable/subtractable than others (see Fig. 4.1 for a diagram of the classification of goods).

It is therefore the rules, rather than the intrinsic properties of the resource, that define how it is classified. Thus, management and property approaches to resolve conflicts related to their scarcity can be addressed in alternative ways to the market and the state. The emphasis is neither on property nor accessibility, but on the rules agreed by communities of practice. The property may be state or private or communal. The management may be communal, or communal-state-private, or stateprivate, etc. This depends on the agreements made. Resources are considered commons when the community is the beneficiary and when it develops the rules that define the uses of the resource, including self-monitoring.

Although there are no fixed or universal rules for the constitution of a commons, their sustainability is based on reciprocity, trust, and cooperation. Ostrom's work

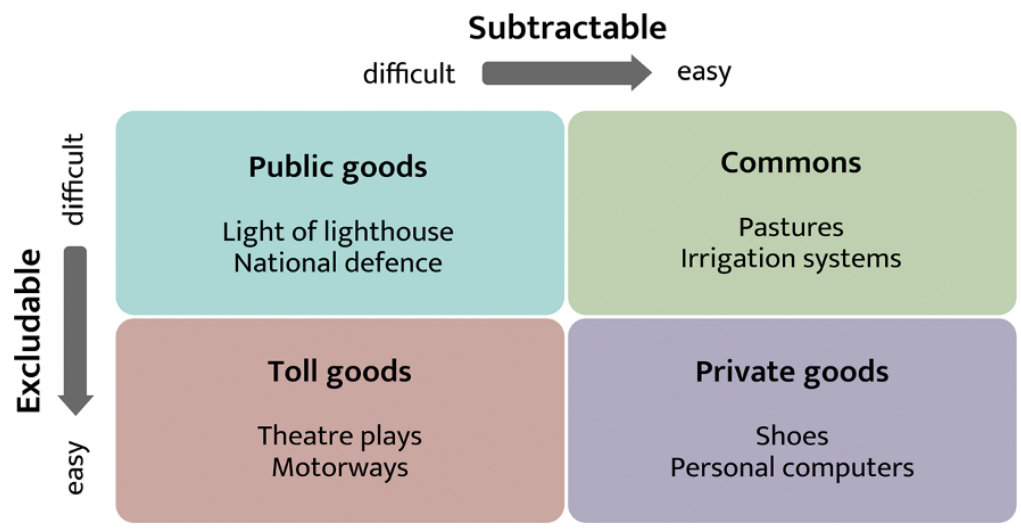

Fig. 4.1 Classification of goods including commons. (Adapted from Ostrom 2009) 
shows that human beings have complex motivational structures beyond personal interest, as well as a greater capacity to solve social problems than the prevailing theories on social dilemmas. In fact, individuals in diverse communities know how to resolve their conflicts, without the intervention of external agents: through selfgovernment, in a decentralised, or polycentric, way. In many different contexts, selfgovernance has reinforced the capacity to solve problems sustainably over long periods of time.

Commons had tended to be ignored in traditional economics analyses. However, the sustainability of certain commons, even over the centuries, has been demonstrated as possible through case studies around the world. It is also highly relevant to mention, albeit very briefly, the convergences of studies on commons and cooperation in different research areas. The emergence of cooperation as a key to the evolution and survival of various complex systems, from the cellular level to socioecological and social structures (Levin 2004), has prompted the research on strategies that lead to stable outcomes in the long term (see Levin 2004 on evolution theory; Axelrod 1984 and 2010 on game theory and political science; MacIntyre 2016 on ethics).

Finally, it should be noted that the classification of certain goods depends on the existing technological possibilities along with the current norms and laws. However, and above all, it depends on the will of those who have competences, responsibilities, and power for defining the resources towards one or another direction. The key question here is: should science be included among public goods as is currently often advocated to prevent its privatisation? Our proposal emphasises that science should be considered a commons in order to achieve its optimal governance.

\section{From Natural Commons to Knowledge as a Commons}

At the beginning of the twenty-first century, Elinor Ostrom, Charlotte Hess, and other researchers began to develop the notion of knowledge as a commons (Hess and Ostrom 2007), extending the concept from the physical to knowledge. Knowledge can be considered as a commons because of its relatively high subtractability and relatively low excludability. These authors explained that, despite various difficulties, similarity can be established because knowledge commons are collectively sustained resources whose accessibility and durability are conditioned by the rules of use.

Science can be understood as a commons mainly because it requires common action within a collaborative project - the result of deliberation and agreement on the rules - to preserve knowledge. Science as a commons is not equivalent to public science but to 'open science or extramural science yet not merchantilized' (Lafuente and Estalella 2015, p. 29). In this sense, open science is related to inclusiveness. Lafuente and Estalella argue that science as a commons does not consist of professional science including citizens in their design and evaluation; it is not the usual science but 'a democratic or postmodern version' (p. 29). Science is a commons due 
to the application of 'contrastive, collective and recursive cognitive practices, a historically differentiated way of producing knowledge, community and commitment' (Lafuente and Estalella 2015, p. 29).

Unlike public and private goods, science as a commons is constituted from and together with its communities, according to the rules of use they themselves establish. Achieving a kind of science that constitutes the common (Dardot and Laval 2019), or a common science (Lafuente and Estalella 2015), requires collaborative action from all those involved - with common objectives, deliberations, infrastructures, and rules of use - as well as attitudes based on trust, reciprocity, and cooperation.

However, such a proposal must be achievable in practice, while science is widely developed on a large scale. Among current good practices of common governance, we can consider some that we have included as sound practices of citizen science, for example, SnowChange, Model Forests, and Biodiversidad Virtual (Table 4.1). Their main shared features are the cooperative management of resources and the co-creation of scientific knowledge beyond (or together with) official institutions. These practices consist of a type of collaborative action that favours a sustainable development of natural resources, as well as the knowledge and methodologies derived from such collaborative actions (see Fig. 4.2). We can also refer to hundreds of projects around the world or to the thousands of publications and studies about socioecological systems among many other topics. Or we can reference Alan Irwin (1995, p. 10) and why he chose environmental issues as a paradigm of the citizen science phenomenon. He indicated three reasons: first, they imply areas of encounter among institutions and citizens; second, environmental risks represent very well other areas of technical and social debate; finally, sustainable development also

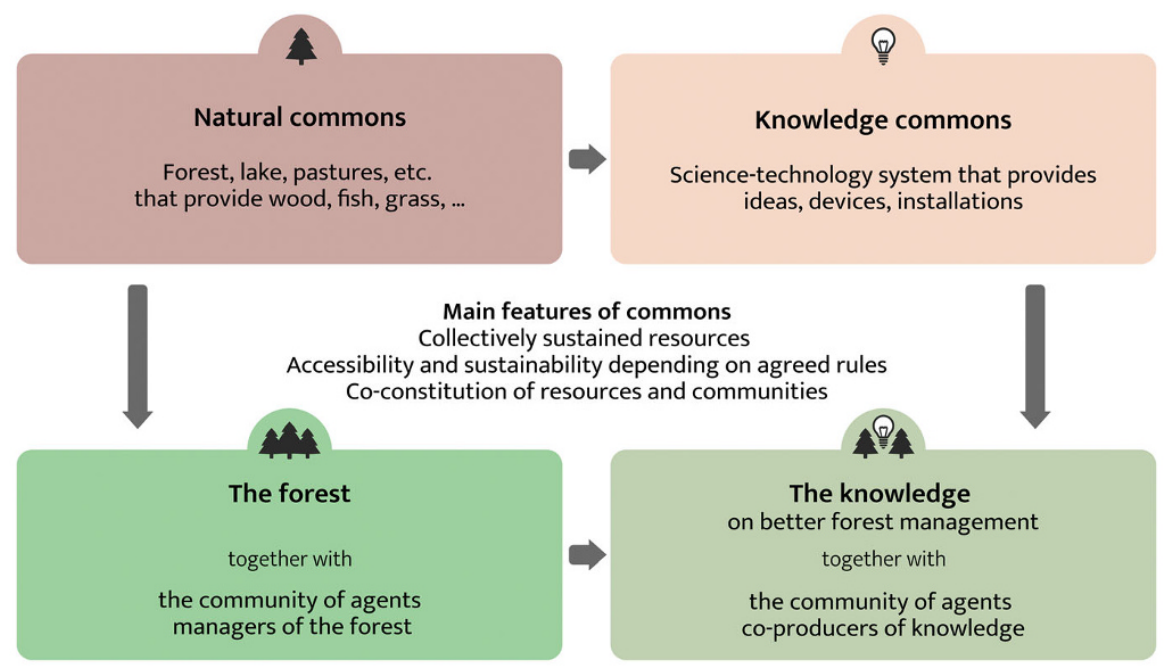

Fig. 4.2 From natural commons to knowledge commons. (Source: prepared by the authors based on the texts of (Hess and Ostrom 2007) and (Dardot and Laval 2019)) 
involves defining the sustainable way of managing science and expertise. Irwin's last reason reflects a central theme in this chapter, together with the concept of cooperation as a methodological foundation of citizen science. Indeed, our proposal for the constitution of science as a commons through citizen science is valid for any cooperative action. Citizen science is particularly powerful because it refers to the sustainability not only of natural resources but of knowledge and science itself.

Citizen science has a particularly relevant role because it (1) allows the development of a multitude of projects in diverse fields with different scopes; (2) favours the constitution of self-regulated and polycentric systems; and (3) supports the conditions of governance and the conservation of the commons.

\section{Citizen Science as a Commons}

Lafuente and Estalella (2015) present an analysis of the role of citizen science in the open science context and specifically as a common science. They understand citizen science as science conducted outside the walls of academia, in which knowledge is developed by virtuous communities. They also highlight that there is not a unique citizen science but rather many citizen sciences (with respect to the diversity of citizen science definitions and interpretations see Haklay et al., Chap. 2, this volume). A relevant comparison is to the maker movement and hacker ethics. Makers and hackers can be defined, respectively, as people who build things and software, sometimes as anti-consumerism, but often for practical reasons based on do-it-yourself (DIY) culture (Toombs et al. 2014). The gift economy translates into sustainable practices and protocols, promoting an open, experimental, inalienable, horizontal, and distributed culture (Lafuente and Estalella 2015). Though not all activity is science, there is a lot of science undertaken by makers and hackers. In this sense, robust citizen science projects - for example, Debian as an emblematic hacker project - help to understand the constitution of scientific knowledge as a commons. In addition, it can be better understood that projects are constituted as knowledge commons. Each one of them consists of a resource sustained by a community, and the community is constituted at the same time as the resource.

Using a different approach we can find initiatives such as Model Forests where open and collaborative science is linked to concepts such as cognitive justice, situated knowledge, and knowledge commons, together with those shared by European policies (inclusion, sustainability, equity). In this way, the sociopolitical aspects of scientific knowledge are understood beyond its (necessary) economic conditions and implications. A set of relevant references for this topic can be found on the Open Collaborative Science Development Network (OCSDNet) website (OCSDNet n.d.).

Understanding that citizen science is a suitable practice to constitute the common implies a double sense, which Dardot and Laval (2019) propose for the common in general: science (and citizen science) is configured as a commons at the same time that, through common action, co-responsible communities are created and 
consolidated. This proposal is illustrated with the examples in Table 4.2 and in the scheme in Fig. 4.2. We understand that citizen science, by overcoming the fictitious fracture between science and its environment, represents a fundamental element for achieving this. However, this is also dependant on the motivations of the involved agents in the governance of a true scientific-technological and sociopolitical progress.

Paraphrasing MacIntyre (2002, p. 107) on the commons concept, we note that in many situations the key question that we should ask is not 'how should $I$ act' but 'how should we act', since the common goods of concrete communities (e.g. the work team) are at stake. These common goods are achieved and enjoyed by individuals as members of communities. An example of success in maintaining the natural commons would be the case of fishing communities. But these achievements are fragile and depend, in large part, on the characteristics that define the agents of these communities. The networks of reciprocity must be created and protected mainly through the development of virtues, including the virtue of recognition of dependence. This is possible through common deliberation about how to define and obtain the shared goods of each community: different but interdependent with one another.

\section{Monitoring Cooperation}

As we have seen, goods are one kind or another not so much per se but by how we use them. Particularly, good management of a commons is linked to cooperation and self-government including monitoring among the members of the community of practice. In this chapter, we have introduced a proposal to understand and manage science - and citizen science - as a commons, that is, as a vulnerable resource that requires rules of use and monitoring, agreed within the communities of use. Vulnerability results from the action of individuals who do not assume their responsibility in the maintenance of a shared resource. They are free-riders who simply consume at the expense of the work of others.

In fact, inequitable treatment of participants can take place, as many citizen science professionals have pointed out. Specifically, Vohland et al. (2019, p. 9) have warned about the need for vigilance 'against instrumentalization by economical interests or the displacement of state duties to citizens'. There are also concerns about the intentions behind its promotion either by institutional science or by policymakers, for example, with respect to possible cost outsourcing (Resnik et al. 2015). In this sense, Mirowski (2018) explicitly argues against citizen science (and open science), understanding it as a tool exclusively for fostering the economy, encouraged by European policies.

With respect to European policy, Schade et al. (Chap. 18, this volume) explain that citizen science has been explicitly placed in different science policy frameworks, in line with the overarching objectives of the Europe 2020 Strategy and in relation to specific areas such as the Digital Agenda, Science 2.0, Responsible 
Research and Innovation (RRI), and Open Science, the latter being the main current framework. Indeed, the European Commission (EC) proposes citizen science as one of the priorities of open science, to 'encourage the inclusion of non-institutional participants, in other words the general public, in the scientific processes' (EC 2016, p. 53) and 're-direct research agendas towards issues of concern to citizens' (EC 2016, p. 54). In the founding document of this initiative, Carlos Moedas (2015, p. 1) states that 'we are moving into a world ... where new knowledge is created through global collaborations involving thousands of people from across the world and from all walks of life'.

The above statements do not seem objectionable, in principle. Nevertheless, they need to be addressed in more detail as they can be limited in scope by a reductionist interpretation of open and citizen science. This requires clarifying the analysis of practices in a system whose main goal appears to be the industrial and commercial exploitation of knowledge.

In this respect, the statement 'the European Union will not remain competitive at the global level unless it promotes Open Science, and relatedly, Open Innovation' (EC 2017, p. 4) can be seen as indicative of the instrumentalisation of 'openness'. Citizens would be seen as 'users' with 'a central and transversal role to play in bringing innovation to the market' (EC 2016, p. 17) rather than as legitimate producers of knowledge.

Of course, this way of interpreting open science and citizen science is not the only one in the EC. The many citizen science projects funded through the last three Research and Innovation Framework Programmes (FPs) have involved thousands of people - including professional scientists, policymakers, companies, the third sector, and citizens in general - actively participating, aware of their co-responsibility for the generation of scientific knowledge and the maintenance and cohesion of their communities and societies. Regarding more specific ethical issues, we refer to research carried out by Tauginienè et al. (Chap. 20, this volume).

If the main feature of citizen science is cooperation (action for constituting commons), specific rules must be established in each project, so that its practice ... by different actors and interest groups ... be monitored and reflected upon carefully' (Vohland et al. 2019, p. 6). The current ambivalence of citizen science towards either strengthening or mitigating its instrumentalisation (Vohland et al. 2019) is related to its condition as a commons. Due to the gradual properties of resources, one type of resource can evolve into another quite easily. Commons are especially vulnerable as they share properties of both public and private goods. In this sense, in a neoliberal context, they face the risk of being privatised.

In short, citizen science represents an important occasion for sociopolitical and cultural-scientific change, which not only favours citizens to be more committed and co-responsible with respect to science but also to achieve better science in all its dimensions. However, it also represents a resource that we need to better understand in order to ensure its preservation. 


\section{Challenges}

Citizen science faces many challenges and must correct and/or prevent bad practices. Though with its own particularities, some challenges are shared with academic science (Resnik et al. 2015). Here we outline some of the most relevant ones:

Epistemic or Cognitive Challenges The implementation of citizen science projects must guarantee the conditions for learning as well as the development of the personal and collective capacities necessary for research. Only in this way can scientific results better be obtained along with socio-cognitive benefits for the participants during the research process.

Ethical Challenges It is necessary to disseminate good examples of citizen science as well as to prevent bad practices, such as misappropriation of research results, exploitation of participants through cost outsourcing, or participation biases. Practices that promote environmental conservation, the generation of knowledge in diverse areas, together with the strengthening of the multiple communities that generate it, must be understood as constituting the commons. Moreover, these same practices must also be understood as knowledge commons. This is the main reason why they must be preserved and promoted.

Political Challenges A better understanding of the scope of cooperation for good governance, as well as of the development of stable forms of cooperation and the strengthening of communities and each one of their members, must be achieved. In that sense, practices favourable to the constitution of the commons should be promoted and preserved. This requires attention to the civic implications of research dynamics, as well as to co-responsibility dynamics in public and common spaces (res publica). European FPs seem to echo these political virtues by introducing the relevance of concepts such as capacity building and recognition (FP7), responsibility (FP7 and F8), and co-creation (FP8 and FP9).

In general, the above-mentioned challenges demand more reflexivity concerning ends and means, particularly in relation to science education and its current promotion through science policies. It seems increasingly necessary to promote a problem-oriented education system, willing and capable of integrating a variety of perspectives and concerns - philosophical, scientific-technical, artistic, etc. More generally, technological and sociopolitical strategies must be consolidated and developed in order to promote polycentric initiatives that are sensitive to interrelation, interdependence, and communication. Examples of these strategies are found in citizen science, such as platforms, shared resources, data repositories, citizen laboratories, and support networks that connect a growing number of projects. The management of these tools requires solid foundations - such as trust-based cooperation - that build and strengthen links for the durability of resources, as well as the flourishing of communities, societies, and their members. 


\section{Future Trends and Recommendations}

Citizen science is situated in a discussion between two poles: a certain enlightened tradition of modernity, which relies on science and progress, and the postmodern relativism that questions science itself and which today is reflected in anti-scientific attitudes and pseudoscientific practices. This is a different discussion, but closely related to, that which occurs between the experts (those who know) and the allegedly lay people (who, not infrequently, also know).

The practice of citizen science presupposes a cognitive and social (pro)active involvement, so that we can truly speak of the co-creation of scientific knowledge. Many complex and/or controversial research questions - that, increasingly, cannot be fully covered by academic research - are suitable to being studied via citizen science methodologies. Thinking about an already foreseeable future, the unstoppable growth in the amount of data will increasingly lead to machine learning techniques, currently used also in citizen science (see Franzen et al., Chap. 10, this volume). However, the previous statements should not be understood or practised in an instrumentalist way. The proposal of the commons starts precisely from the premise - theoretical and empirical - that cooperation, with all that it involves, is the best solution for all concerned with matters of general interest. But its application is neither simple nor homogeneous and therefore requires continuous reflection and surveillance by communities.

Citizen science has been proposed in this chapter as key to the constitution of science as a commons, by allowing the development of a multitude of projects based on cooperation for the preservation of natural or knowledge commons. The corresponding network of agents and communities not only favours the conditions of governance, sustainability, and quality of knowledge, but also comes with important cultural, social, and political changes. Understanding science - and citizen science - as a commons brings to the fore a challenge inherent in the concept. The constitution of a commons requires specific conditions that must, in turn, be created and preserved.

In society in general (politics, education, art, science, sport, etc.) we need:

- A better understanding of the meaning, scope, and benefits of cooperation and, consequently, the promotion of this governance model, through research, education, and policies, whether governmental or not.

- A wide diffusion of the concept of the commons that transcends the public-private dichotomy, highlighting the protagonism of citizens themselves (including professional scientists and politicians) in the infinite possibilities of common spaces.

In each citizen science project, the following tasks are also needed:

- The establishment of rules within the communities that shape the projects.

- Careful monitoring of the projects (especially the top-down ones) so that the participants are considered not as users but as collaborators, members of the research team, each one with their own responsibilities, be they major or minor. 
This monitoring translates into recognition of citizen scientists both in the development of research and in the research products derived from it.

- Monitoring also refers to action against free-riders who can be citizen scientists, professional scientists, managers, communicators, or politicians.

Citizen science is already part of the transition towards a different culture, where cooperation is the guiding principle in all shared areas, for example, in governance models, in education, health, culture, and communication. However, this will only happen if we intend to address it in the day-to-day of each project. Since many commons have existed for decades, even centuries, we know that this proposal can be achieved.

Acknowledgements Maite Pelacho's contribution was supported by the Spanish Foundation of Science and Technology and the Spanish Ministry of Science and Innovation (FCT-18-14225). Maite is especially grateful to Javier Belastegui, predoctoral researcher at the University of the Basque Country UPV/EHU, for his valuable comments on the content of this chapter. Hannot Rodríguez's contribution was supported by the Spanish Ministry of Economy and Competitiveness and the European Regional Development Fund (FFI2015-69792-R), the Vice-rectorate for Research of the University of the Basque Country UPV/EHU (PPGA19/23, and GIU19/051), and the Basque Government's Department of Education (IT1205-19). All the authors thank the editors and reviewers for their careful and enthusiastic work.

\section{References}

Axelrod, R. (1984). The evolution of cooperation. New York: Basic Books.

Axelrod, R. (2010). Beyond the tragedy of the commons: A discussion of governing the commons: The evolution of institutions for collective action. Perspectives on Politics, 8(2), 580-582.

Bonney, R. (1996). Citizen science: A lab tradition. Living Birds, 15(4), 7-15.

Boutang, Y. M. (2011). Cognitive capitalism. London: Polity.

Broncano, F. (2006). Entre ingenieros y ciudadanos. Filosofía de la técnica para días de democracia. Madrid: Montesinos.

Callon, M. (1994). Is science a public good? Fifth Mullins Lecture, Virginia Polytechnic institute. Science, Technology \& Human Values, 19(4), 395-424.

Dardot, P. \& Laval, C. (2019). Common: On revolution in the 21st century (trans: MacLellan, M.). London: Bloomsbury.

David, P.A. (2008). The historical origins of 'open science'. An essay on patronage, reputation and common agency contracting in the scientific revolution. Capitalism and Society, 3(2), Article 5.

Debian (n.d.). About Debian. https://www.debian.org/intro/about. Accessed 29 Feb 2020.

EC (European Commission). (2016). Open innovation, open science, open to the world - A vision for Europe. Luxembourg: Publications Office of the EU.

EC (European Commission). (2017). OSPP-REC: Open science policy platform recommendations. Luxembourg: Publications Office of the EU.

Fischer, F. (2000). Citizens, experts, and the environment. The politics of local knowledge. Durham: Duke University Press.

Frickel, S., Kempner, J., Gibbon, S., Howard, J., Ottinger, G., \& Hess, D. (2009). Undone science, charting social movement, and civil society challenges to research agenda setting. Science, Technology \& Human Values, 35(4), 444-473. 
Funtowicz, S., \& Ravetz, J. (1997). Environmental problems, post-normal science, and extended peer communities. Études et Recherches sur les Systèmes Agraires et le Développement, 30, $169-175$.

Gibbons, M. (1999). Science's new social contract with society. Nature, 402, C81-C84.

Goldman, A. I. (1999). Knowledge in a social world. Oxford: OUP.

Haklay, M. (2015). Citizen science and policy: A European perspective. Washington, DC: Woodrow Wilson International Center for Scholars.

Hess, D. L. (2007). Alternative pathways in science and industry: Activism, innovation, and the environment in an era of globalization. Cambridge, MA/London: The MIT Press.

Hess, C., \& Ostrom, E. (Eds.). (2007). Understanding knowledge as a commons: From theory to practice. Cambridge, MA/London: The MIT Press.

Hohendahl, P. U. (2011). Humboldt revisited: Liberal education, university reform, and the opposition to the neoliberal university. New German Critique, 113(38), 159-196.

International Model Forest Network (IMFN). (n.d.). History of the IMFN. https://imfn.net/about/ history-of-the-imfn/. Accessed 29 Feb 2020.

Irwin, A. (1995). Citizen science: A study of people, expertise and sustainable development. London/New York: Routledge.

Irzik, G. (2013). Introduction: Commercialization of academic science and a new agenda for science education. Science \& Education, 22(10), 2375-2384.

Jasanoff, S. (2003). Technologies of humility: Citizen participation in governing science. Minerva, 41(3), 223-244.

Kitcher, P. (2001). Science, truth and democracy. Oxford: Oxford University Press.

Lafuente, A., \& Estalella, A. (2015). Ways of science: Public, open, and commons. In S. Albagli, M. L. Maciel, \& A. H. Abdo (Eds.), Open science, open issues (pp. 27-57). Brasilia: UNIRIO.

Leach, M., Scoones, I., \& Wynne, B. (Eds.). (2005). Science and citizens: Globalisation and the challenge of engagement. London: Zed Books.

Leshner, A. I. (2003). Public engagement with science. Science, 299(5609), 977.

Levin, S. A. (2004). Public goods in relation to competition, cooperation and spite. Proceedings of the National Academy of Sciences, 111(3), 10838-10845.

MacIntyre, A. (2002). Dependent rational animals: why human beings need the virtues. Chicago/ La Salle: Open Court.

MacIntyre, A. (2016). Ethics in the conflicts of modernity: An essay on desire, practical reasoning and narrative (2nd ed., pp. 176-183). Cambridge: Cambridge University Press.

Madison, M. J. (2014). Commons at the intersection of peer production, citizen science, and big data: Galaxy zoo. In B. M. Frischmann, M. J. Madison, \& J. Strandburg (Eds.), Governing knowledge commons (pp. 209-254). Oxford: Oxford University Press.

Madison, M. J., Frischmann, B. M., \& Strandburg, K. J. (2019). Knowledge commons. In B. Hudson, J. Rosenbloom, \& D. Cole (Eds.), Routledge handbook of the study of the commons (pp. 76-90). Abingdon/New York: Routledge.

Mirowski, P. (2018). The future(s) of open science. Social Studies of Science, 48(2), 171-203.

Moedas, C. (2015). Open innovation, open science, open to the world (SPEECH/15/5243). Presented at a new start for Europe: Opening up to an ERA of Innovation Conference. 22 June 2015. Brussels.

Nowotny, H., Pestre, D., Schmidt-Aßmann, E., Schulze-Fielitz, H., \& Trute, H.-H. (2005). The public nature of science under assault. Politics, markets, science and the law. Berlin/Heidelberg: Springer.

OCSDNet (Open Collaborative Science and Development Network). (n.d.). Open \& collaborative science manifesto reading list. https://ocsdnet.org/wp-content/uploads/2015/04/OCS-Mani festo-Reading-List.pdf

Ostrom, E. (1990). Governing the commons: The evolution of institutions for collective action. Cambridge: Cambridge University Press. 
Ostrom, E. (2009, 8 December). Beyond markets and states: Polycentric governance of complex economic systems (Lecture - Nobel Prize Discourse). https://www.nobelprize.org/uploads/ 2018/06/ostrom_lecture.pdf

Ostrom, V., \& Ostrom, E. (1977). Public goods and public choices. In E. S. Savas (Ed.), Alternatives for delivering public services: Toward improved performance. Boulder: Westview Press.

Quine, W. V., \& Ullian, J. S. (1970). The web of belief. New York: Random House.

Radder, H. (2010). The commodification of academic research. Science and the modern university. Pittsburgh: University of Pittsburgh Press.

Resnik, D. B., Elliott, K. C., \& Miller, A. K. (2015). A framework for addressing ethical issues in citizen science. Environmental Science \& Policy, 54, 475-481.

Toombs, A.L., Bardzell, S., \& Bardzell, J. (2014). Becoming makers: Hackerspace member habits, values and identities. Journal of Peer Production, 5. https://www.academia.edu/9043637/ Becoming_Makers_Hackerspace_Member_Habits_Values_and_Identities

Vermeir, K. (2013). Scientific research: Commodities or commons? Science \& Education, 22(10), 2485-2510.

Vohland, K., Weißpflug, M., \& Pettibone, L. (2019). Citizen science and the neoliberal transformation of science - An ambivalent relationship. Citizen Science: Theory and Practice, 4(1), 25. https://doi.org/10.5334/cstp.186.

Weber, K., Pallas, F., \& Ulbricht, M. R. (2019). Challenges of citizen science: Commons, incentives, organizations, and regulations. The American Journal of Bioethics, 19(8), 52-54.

Maite Pelacho is a researcher and project manager at Ibercivis Foundation. She coordinates the Observatory of Citizen Science in Spain. She is currently working on her PhD research at the University of the Basque Country UPV/EHU, on citizen science and the epistemology and the political philosophy of science, particularly on the proposal of considering science as a commons. She has a background in physics, environmental issues, education and philosophy of science.

Hannot Rodríguez is an associate professor at the Department of Philosophy of the University of the Basque Country UPV/EHU (Faculty of Arts), Vitoria-Gasteiz, Spain. His research focuses on risk governance of emerging technologies, responsible innovation, and philosophical and social dimensions of science and technology.

Fernando Broncano is a professor at Universidad Carlos III de Madrid. He works in philosophy of technology and social and political epistemology. He considers knowledge in the context of a material culture that shapes societies.

Renata Kubus is an entrepreneur and researcher in innovation ecosystems, collective intelligence, citizen science, and the future of work. She is the founder of Network for Collective Intelligence Development (CID-N) and an active member of several scientific associations, including the AUDESCO/ECSA Spain and the Scientists Dating Forum.

Francisco Sanz is the executive director of the Ibercivis Foundation. He has combined work as associate professor at the University of Zaragoza with research at the Institute of Biocomputation and Physics of Complex Systems. Since 2008, he has promoted citizen science, creating diverse projects - distributed computing, collective intelligence, and maker projects, among many others.

Beatriz Gavete is a researcher in the Department of Philosophy at the University of Zaragoza and a $\mathrm{PhD}$ candidate at the same university. Her research, in political philosophy, is focused on social movements, anti-hierarchical forms of organisation, and the principle of 'the common'. 
Antonio Lafuente has researched knowledge transmission processes from the elites to lay people and from the centres to the peripheries. He is currently interested in the relationship between the commons and technology and, also, in social movements understood as cognitive agents. He is based at the History Institute (CSIC) in Spain.

Open Access This chapter is licensed under the terms of the Creative Commons Attribution 4.0 International License (http://creativecommons.org/licenses/by/4.0/), which permits use, sharing, adaptation, distribution and reproduction in any medium or format, as long as you give appropriate credit to the original author(s) and the source, provide a link to the Creative Commons license and indicate if changes were made.

The images or other third party material in this chapter are included in the chapter's Creative Commons license, unless indicated otherwise in a credit line to the material. If material is not included in the chapter's Creative Commons license and your intended use is not permitted by statutory regulation or exceeds the permitted use, you will need to obtain permission directly from the copyright holder.

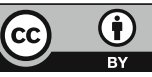

